\title{
WORKING PAPERS
}

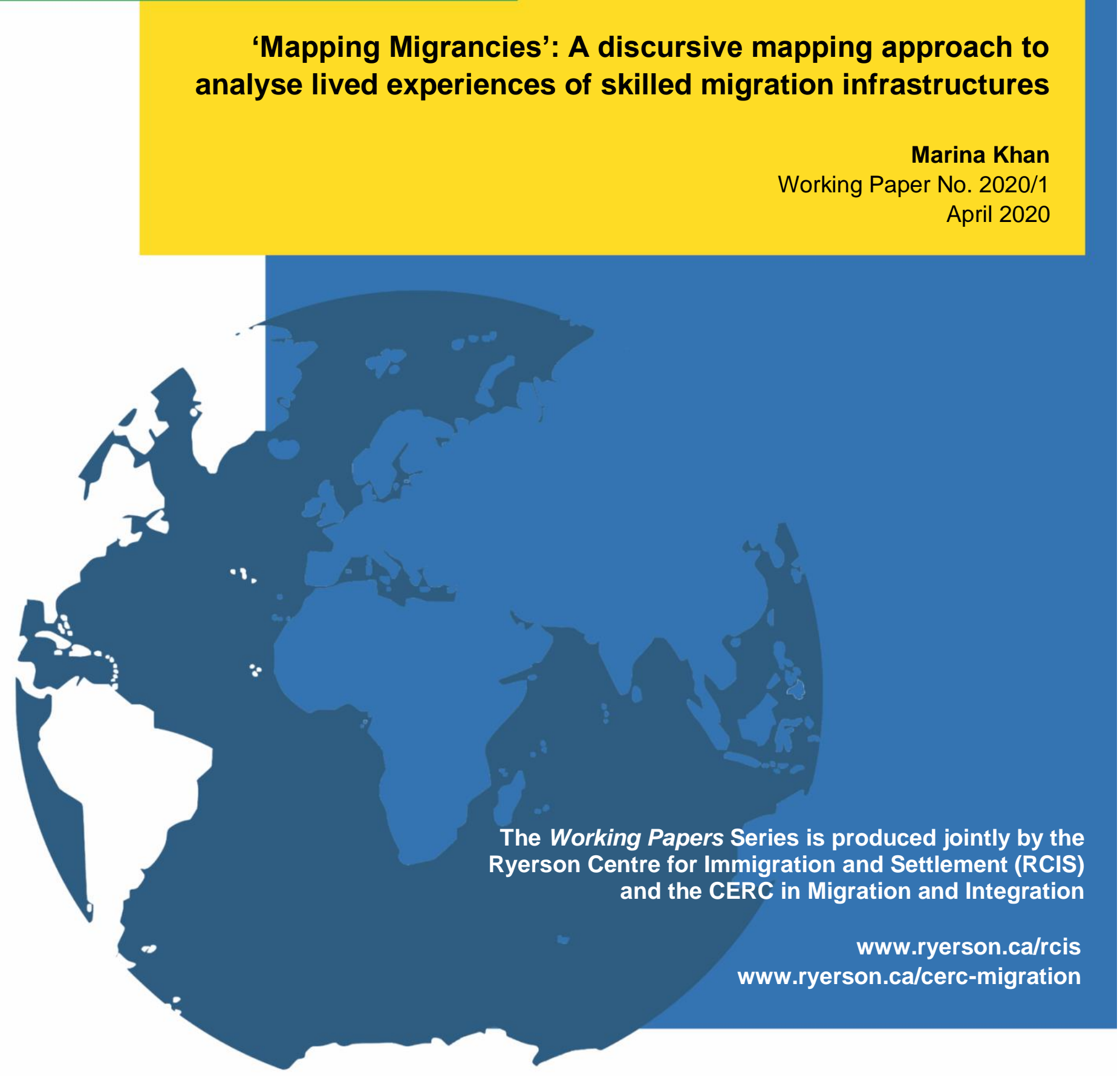




\title{
Working Paper
}

No. $2020 / 1$

\section{'Mapping Migrancies': A discursive mapping approach to analyse lived experiences of skilled migration infrastructures}

\author{
Marina Khan \\ Western Sydney University
}

Series Editors: Anna Triandafyllidou and Usha George

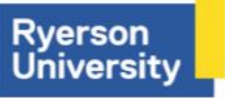

Canada Excellence
Research Chair in
Migration \& Integration

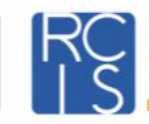

The Working Papers Series is produced jointly by the Ryerson Centre for Immigration and Settlement (RCIS) and the CERC in Migration and Integration at Ryerson University.

Working Papers present scholarly research of all disciplines on issues related to immigration and settlement. The purpose is to stimulate discussion and collect feedback. The views expressed by the author(s) do not necessarily reflect those of the RCIS or the CERC.

For further information, visit www.ryerson.ca/rcis and www.ryerson.ca/cerc-migration.

ISSN: $1929-9915$

(7)(9) Creative Commons Attribution-Noncommercial-No Derivative Works 2.5 EY No No Canada License 


\begin{abstract}
The recent 'infrastructural turn' in migration studies has provided valuable insights into the emergence and functions of different aspects of migration infrastructure such as the commercial migration industry, social networks, and technological innovations (Xiang and Lindquist 2014). The focus of current scholarship, however, has been on how these infrastructures mobilise migrants, predominantly across irregular migration pathways. There remains a gap in exploring infrastructures of formal migration, and their entanglements with migrants' own subjectivities. This paper reports on a research project that explores this gap by arguing for a new research agenda on migration infrastructure. The study uses a 'discursive mapping' approach involving in-depth interviews and mind-maps sketched by 27 research participants based in Australia and Canada as they narrated their migration experience. This paper draws upon the experiences of three migrants to illuminate how their journeys are intertwined with and shaped by migration infrastructures - particularly media and regulatory processes. By (re)centring the infrastructural focus on migrants' own agencies, desires, and life-courses, this study presents nuanced understandings of the lived experience of skilled migration infrastructures.
\end{abstract}




\section{Table of Contents}

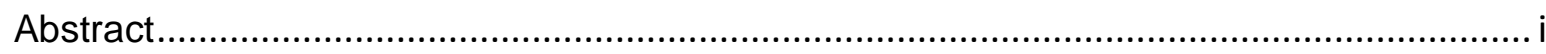

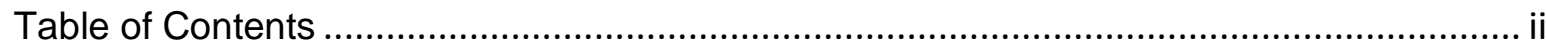

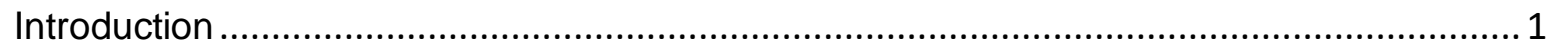

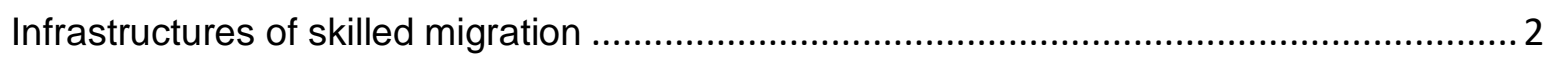

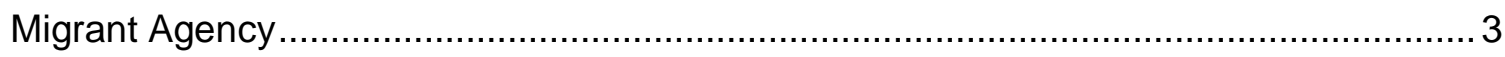

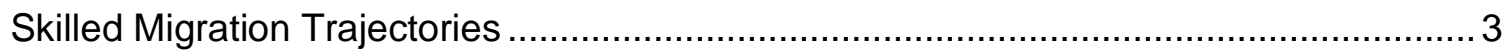

Multiple Infrastructural Processes ……………………...................................

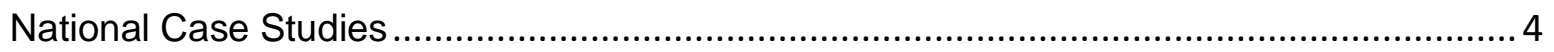

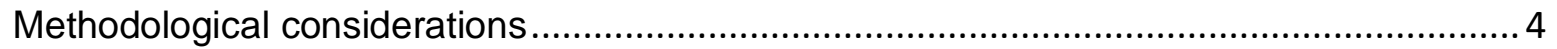

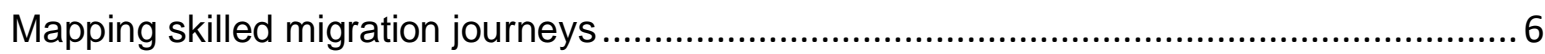

Lorraine

Azwa

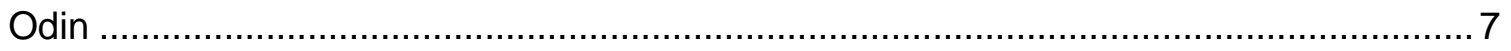

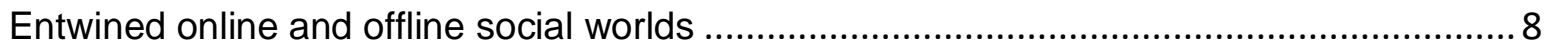

Regulatory frameworks and migrant subjectivities ........................................................ 10

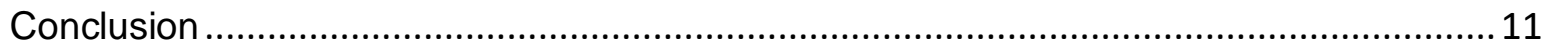

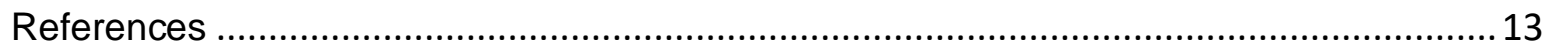




\section{Introduction}

The term 'migration infrastructure' stems from the fundamental significance of infrastructures to all aspects of life. Infrastructures are what define our society by "mediating exchange ... bringing different people, objects, and spaces into interaction and forming the base on which to operate modern economic and social systems" (Larkin 2013, p. 330). Xiang and Lindquist (2014, p. 124) explain 'migration infrastructure' as "the systematically interlinked technologies, institutions and actors that facilitate and condition mobility." According to Xiang and Lindquist's (2014) theorisation, migration infrastructure consists of five broad but interlinked dimensions: the commercial, the regulatory, the technological, the humanitarian and the social. There remains, however, a gap in exploring the multiplicity of infrastructural processes within singular and individual migration trajectories, and migrants' own subjectivities within these encounters, which hinders our capacity to conceptualise holistically the process of migration. This paper reports on an ongoing research project that explores this gap by arguing for a new research agenda on migration infrastructure, that begins by 'mapping' skilled migration journeys in a global context.

Infrastructural developments in migration have paradoxically made mobility both easier and complex at the same time. A host of commercial services operating alongside neoliberal migration policies have on one hand created greater access to mobility. On the other hand, regulatory apparatuses operating in national interests such as labour market outcomes and security concerns have made migration more difficult (Xiang \& Lindquist, 2014). Increase in transnational connectivity intensifies the complexity and states are constantly implementing strategies to manage the rate, scale, and pace of migration (Mcauliffe \& Ruhs, 2017). Amidst these arrangements, migrants have to learn to strategize as they adjust their plans in shifting political contexts (Aparna \& Shanpendonk, 2018). As a result, infrastructural mechanisms, and migrant trajectories have become enmeshed in complex entanglements that need closer examination.

Research focusing on the 'infrastructural turn' in migration has primarily focused on exploring (i) migration facilitation and control (Cranston et al., 2018), and (ii) How infrastructural mechanisms, industries, and systems function (Xiang and Lindquist 2014; Lin et al., 2016). Such scholarship, hence, focuses largely on the infrastructural aspects, ignoring migrants' own roles within their migration journeys. Research on migrants' interactions with the infrastructure often only covers single aspects of the infrastructure such as migration intermediaries or social networks or digital connectivity (Groutsis et al., 2015; Harvey et al., 2018). I argue, however, that migration experiences are made up of combinations of multiple interlinked components of the infrastructure and a holistic picture can only emerge when migrants' experiences of navigating multiple infrastructures are investigated. This paper explores these encounters through three migrants' trajectories as they intersect with digital and regulatory infrastructural mechanisms along different phases of their journey. By (re)centring the infrastructural focus on migrants' own agencies, desires, and life-courses, this study presents nuanced understandings of the lived experience of skilled migration infrastructures.

In the following sections, I review extant empirical research, and present arguments underlining the importance of exploring skilled migration infrastructures. This is followed by an analysis of the national case studies including a brief definition of skilled migration in the context of this study, the methodological considerations for this research, and an overview of mental mapping as a method. I then turn to the findings which zoom into migrants' encounters with technology and regulatory infrastructures, to demonstrate the intricacies of skilled migration processes that span beyond categorical classifications and dichotomies of arrival/departure, temporary/permanent, skilled/non-skilled. In doing so this paper attempts to humanise the process of migration by shifting the infrastructural gaze from infrastructures 
to experiences. I argue that this shift is critical in better understanding migration infrastructures that are not simply processes that migrants go through but are lived, felt and communicated with as they collide with migrants' social worlds and individual subjectivities.

\section{Infrastructures of skilled migration}

This section provides a brief historical context and recent theoretical developments on migration infrastructure. This is a followed by a review of the existing literature and the gaps that have been identified, particularly in relation to skilled migration. An overview of Australia and Canada as national case studies is also provided along with the rationale for not using policy classifications for skilled migration.

The first attempts at unpacking the processes of migration can be traced back to the late 1990s, when the term 'migration industry' started emerging in academic literature. The migration industry provided a means to understand migration flows in light of states intensifying their control on movements across territorial boundaries (Spener, 2009). These earlier studies adopted a business-centric approach in explaining international migration as characterised by institutionalised networks of recruitment, travel agents, transport operators, legal, and advisory firms amongst others (Salt \& Stein, 1997). However, as discussed in the preceding section, migration mediation involves more than just commercial processes. Various interconnected arrangements are at play in making migration happen such as family and social networks, regulatory systems and policies, and transnational connectivity. 'Migration infrastructure' as a conceptual framework, argues to encompass these greater aspects and provide the bigger picture of the courses of migration mediation. This approach calls upon a reconceptualization of the migration process through shifting focus to infrastructure rather than the historical and dominant focus on flows. The infrastructure framing, as it is currently understood, however, does not sufficiently cover all aspects of the migration process by concentrating heavily on departure arrangements (Xiang \& Lindquist, 2014; Alpes, 2017; Xiang, 2017; Lindquist, 2017; Thieme, 2017; Žabko et al., 2018; Goh et al., 2017; Harvey et al., 2018; Spaan \& van Naerssen, 2018). As the findings in this paper demonstrate, 'arriving' does not end the infrastructuring process. "Migrants' material becomings do not end in a new state of being," and aspirations, goals, and desires for a "new becoming" shape migration trajectories further (Papadopoulos \& Tsianos, 2008, p. 210; Boccagni, 2017, p. 1). Furthermore, migration trajectories are also characterised by unexpected detours, contingencies, reimagined objectives, and mixed motivations that are not represented adequately within the infrastructure analyses (Robertson, 2017). Therefore, in this paper, I expand upon the conceptual and theoretical understandings of migration infrastructure through investigating individual experiences.

In examining the existing literature on migration infrastructure, I identify three key gaps. Firstly, studies on migration infrastructure have largely emphasized on the ways in which infrastructural systems facilitate and control migration - i.e. how migrants are moved. However, how migrants themselves perceive, seek and use infrastructure has received limited exploration. Secondly, much of the literature in this field investigates processes of irregular migration. Less attention is paid to more regular and formal types of migration such as international students, sponsored workers, and family migration. Therefore, for this study, I focus on migrants who 'self-identify' as skilled migrants, which I further explain in the methodological section of this paper. Finally, a vast array work on infrastructures emphasizes the role of meso-level actors and systems (Spener, 2009; Cranston et al., 2018). As discussed throughout this paper, several other arrangements exist within the infrastructure, and these arrangements are interlinked across scales (micro, meso and 
macro). A focus on the lived experience of infrastructures uncovers some of these actions and entanglements.

\section{Migrant Agency}

Migration infrastructure as a growing field of study is concerned largely with the orders, structures and 'technical objects' that shape and morph migration (Lin et al., 2016). These structures include organisational frameworks such as global mobility services (Cranston, 2018), recruitment and training (Xiang, 2017), travel documentation (Cho 2017), physical infrastructures such as airports and surveillance systems (Hirish, 2017; Liu \& Lin, 2017), and technological interventions including telecommunications and media platforms (SánchezQuerubín \& Rogers, 2018). How migrants themselves perceive, seek and use these infrastructures has received limited exploration. The findings presented in this paper reveal that migration includes critical human interventions on the migrants' part such as decision making (Spaan \& Naerssen, 2018; Triandafyllidou, 2017), strategy (Franck et al., 2018; Aparna \& Schapendonk, 2018) and aspiration (Collins, 2018; Folse, 2017). I argue in fact, that migrants' personal interpositions often determine which, and how infrastructure services will be utilised in order to achieve particular goals across different stages and phases of the migration journey (Franck et al., 2018).

\section{Skilled Migration Trajectories}

Empirical studies conducted within the analytical frame of migration infrastructure are heavily focused on informal and irregular types of migration. These pathways predominantly include low-skilled labour migration (Xiang \& Lindquist, 2014; Xiang, 2017; Lindquist, 2017; Schapendonk et al., 2018; Schwarz, 2018), refugee migration (Kleist, 2017; Massa, 2018), forced migration (Schapendonk, 2018; Connell et al., 2018), and marriage migration (Yeoh et al., 2017). While these pathways are indeed complicated and require critical interventions, recent works on student migration by Robertson (2017), and migrant encounters with global mobility industry by Cranston et al. (2018) provide insights into the intricacies of regular and formal migration as well, which is becoming increasingly complex. Within skilled migration as well, scholarly research is often based on policy categories (Czaika \& Parsons, 2017; Harvey et al., 2018; Robertson, 2018). I argue, however, for a shift in scholarly observation of skilled immigration from 'categories' to 'pathways.' This is because contemporary skilled migration, as this paper shows, is a multi-step process involving various temporary visas, transit points, and diverse economic, social, and cultural motivations.

\section{Multiple Infrastructural Processes}

While migration infrastructures have been analysed as complex operational systems comprising of multiple components (Xiang \& Lindquist, 2014), studies have dominantly focused upon the commercial aspect of infrastructure, framing migration as 'big business' (Gammeltoft-Hansen, 2013). Studies under this realm have ranged from exploring border securitization processes (Dijstelbloem, 2017) to brokerage mechanisms (Faist, 2014). Literature on meso-level commercial actors includes explorations of informal or semi-formal migration brokerage (Alpes, 2017; Chan, 2017; Tuckett, 2018; Yeoh et al., 2017; Fernandez, 2013; Lindquist, 2017), formal intermediary services (Groutsis et al., 2015; Underhill et al., 2016; Harvey et al., 2018; Žabko et al., 2018; Koh \& Wissink, 2018), international education 
systems (Thieme, 2017; Beech, 2018; Lim \& Pham, 2016; Robertson, 2017; Liu \& Lin, 2017), and transnational recruitment processes (Cranston, 2018; Cranston, 2016; Xiang, 2017; Friberg, 2016; McCollum \& Findlay, 2018). However, while the maps in this paper confirm that commercial processes are a significant aspect of skilled migration, they also stress upon the interlinked social, technological, and regulatory processes that are occurring simultaneously, and being shaped, and (re)created by migrants' own thoughts and actions (Xiang \& Lindquist, 2014).

\section{National Case Studies}

The two destinations chosen for this study - Australia and Canada - rely heavily on skilled migration, and in comparison, to other immigration destinations, have adopted explicitly selective migration policies through points-based systems to attract skilled workers (Hawthorne, 2015; Koslowski, 2013). The fieldwork was conducted in New South Wales and Victoria in Australia and in Ontario and Quebec in Canada. The four sites chosen are not only popular destinations for points-based skilled migration, but also for the highest regional/provincial nomination visas and employment sponsorship visas (ABS, 2019; Statista, 2019; Hopkins, 2016). While this is not a comparative study of skilled migration processes between Australia and Canada, adopting a multi-sited approach allowed explorations of diverse experiences in a global skilled migration context. While skilled visa categories significantly exceed family, and humanitarian entrants in both countries, recent research suggests that these pathways are becoming increasingly complex in both nations, characterised by elongated routes, and multi-step processing (Walsh, 2014; Mares, 2016). These broader shifts set the scene for infrastructural interventions, as migrants negotiate and adjust their plans, actions, and identities across changing policies and statuses (Robertson, 2014; Ghosh, 2014).

These transformations in skilled migration also provide context to the departure from using policy categories as a means of analysis in this study. Alongside explicit state or employer sponsored, and independent points-tested skilled migration options, both countries include other types of 'skilled' visas such as post-graduate work, investor and business innovation categories, domestic work, working-holiday, labour agreements, and staff exchange arrangements. Some of these categories are not clearly identified as skilled visas in national policy assessments and statistics (DHA, 2019). Moreover, focusing strictly on skilled migration classifications neglects important life-courses as migrants often switch across and between different types of temporary visas until they obtain permanent residency (PR) (Robertson, 2017; Baas, 2017; Ramos, 2018). Migrants arriving on family and other dependent visas also fill skill shortages and make significant economic contributions but are not classified as skilled immigrants. Therefore, for the purposes of this study, skilled migration is understood as a trajectory consisting of multiple, processes and I focus on migrants who self-identify as skilled.

\section{Methodological considerations}

In this section I highlight the key methodological considerations for this project including my own positionality in conducting this study and using discursive mapping as a method. My own experience of an ongoing migration journey of nine years has been one of the main motivations for this study. Being on a skilled migration pathway for both Australia and Canada allowed me to approach the interviews from an 'insider' perspective, where I could relate to participants' experiences and establish a relationship of trust and empathy. 
Insights obtained from an 'insider' perspective, however, did not only rely on shared experiences and connections but also allowed for exploration of convergences and divergences in these experiences (Voloder, 2009). My experiences were also visually represented in my own mental map which was provided as a sample for participants and probed them into thinking about the various processes they went through, illuminating intricate and hidden infrastructural encounters, which I unpack further in the following sections.

The focus for this study is following migration trajectories, i.e. following migrants through their migration processes and journeys and noting key infrastructural encounters they experience along the way. In order to achieve this, mental mapping has been used alongside in-depth interviews, which I have termed as 'discursive mapping.' The goal of discursive mapping is not only to visualise the critical junctures of migration infrastructure, but to discuss in detail the types of infrastructures that were encountered, how they were navigated or utilised, and how they shaped participants' migration experiences (Groutsis et al., 2015). Mapping as a method in migration studies is relatively recent and has largely been utilised in a geographical sense. The 'spatial turn' in social theory and cultural studies, however, goes beyond geography and "mapping has emerged as a trope of spatial thinking and analysis" (Rechniewski \& Graves, 2015; Jung, 2014). As such, the discursive maps presented in this paper depict lived experiences of migration infrastructure that are embedded in social, emotional, and aspirational aspects of migrants' lives.

The maps were either sketched on paper or constructed using a mind mapping application called 'simple mind.' Participants were asked questions using Lynch's (1960) general guidelines which included: (i) a broad description of the journey, (ii) an elaboration of the different phases, and (iii) a description of elements depicted. The purpose of working with participants to create their own migration map was to illuminate their individual encounters with people, services, technologies, and networks and the relationships between these encounters (Campos-Delgado, 2018).

A total of 27 interviews were conducted across Sydney, Melbourne, Toronto, and Montreal. Contrary to geographical cartographies that simplify skilled migration journeys, the discursive maps in this study uncover how 'messy' and onerous these processes are. The maps also highlight the diversity of the skilled migration experience, represented in three narratives presented in this paper. The accounts chosen, illustrate some of the most common pathways for skilled migrants in both countries, and are also comparable as the processes are contextually similar in both policy settings. For instance, Odin's points-tested skilled independent route in Australia is comparable to Canada's Express Entry system, Azwa's two-step partner visa process is similar to partner migration in Australia, and Lorraine's employer sponsored visa is parallel to Canada's temporary foreign worker program. Policy differences that exist between the two countries on these pathways are only minor with regards to the broader aims of this study, which is interested in 'how' these processes are experienced.

The narratives chosen also provide a good representation of the total sample, with eight of the 27 participants on permanent skilled pathways, seven on temporary skilled visas, and five on partner visas. The overlaps within the three narratives contextualise their selection further. For example, Azwa and Odin are both on different ends of the partner visa process, Lorraine and Azwa are on different visas but are going through a two-step migration process leading to PR, while Odin and Lorraine highlight similar aspirations for career and future mobility. The three accounts are also connected by thematic similarities on the use of digital media and regulatory infrastructures that were encountered in the authors' diverse pathways. These narratives further speak to the methodological focus of this paper in showcasing diverse routes, considerations, and sub-categories of skilled migration that are often omitted or underrepresented within official depictions of economic migration. The 
authors' decisions, motivations, social roles, and aspirations in experiencing these infrastructures have been uncovered in greater detail in the subsequent sections.

\section{Mapping skilled migration journeys}

The migration stories represented in this paper were different from each other in terms of pathways and experiences, but thematically linked through the infrastructures that the three participants discussed. While their maps depict various aspects of migration infrastructure, their conversations centred around encounters with technology and regulatory frameworks. The three stories, however, demonstrate unique experiences with these infrastructures characterised by individual circumstances. These aspects are covered in more detail in the following sections. A brief overview of participants and their maps has been provided below.

\section{Lorraine}

Lorraine arrived in Sydney from Scotland with her husband and three children in early 2019. She received an employer sponsored visa to work as a lecturer at a university. She had previously visited Australia in 2000 on a working holiday visa and returned again in 2011 with her family for a holiday in hopes to convince them to move permanently. Her plans only materialised in 2018, when she applied for a job in Sydney, which was successful. Her work visa was organised by the university and the process was relatively smooth and quick. Her biggest challenge, however, was migrating with her family which involved various considerations around her children's schooling, husbands' career, their social networks, and selling their home in Scotland.

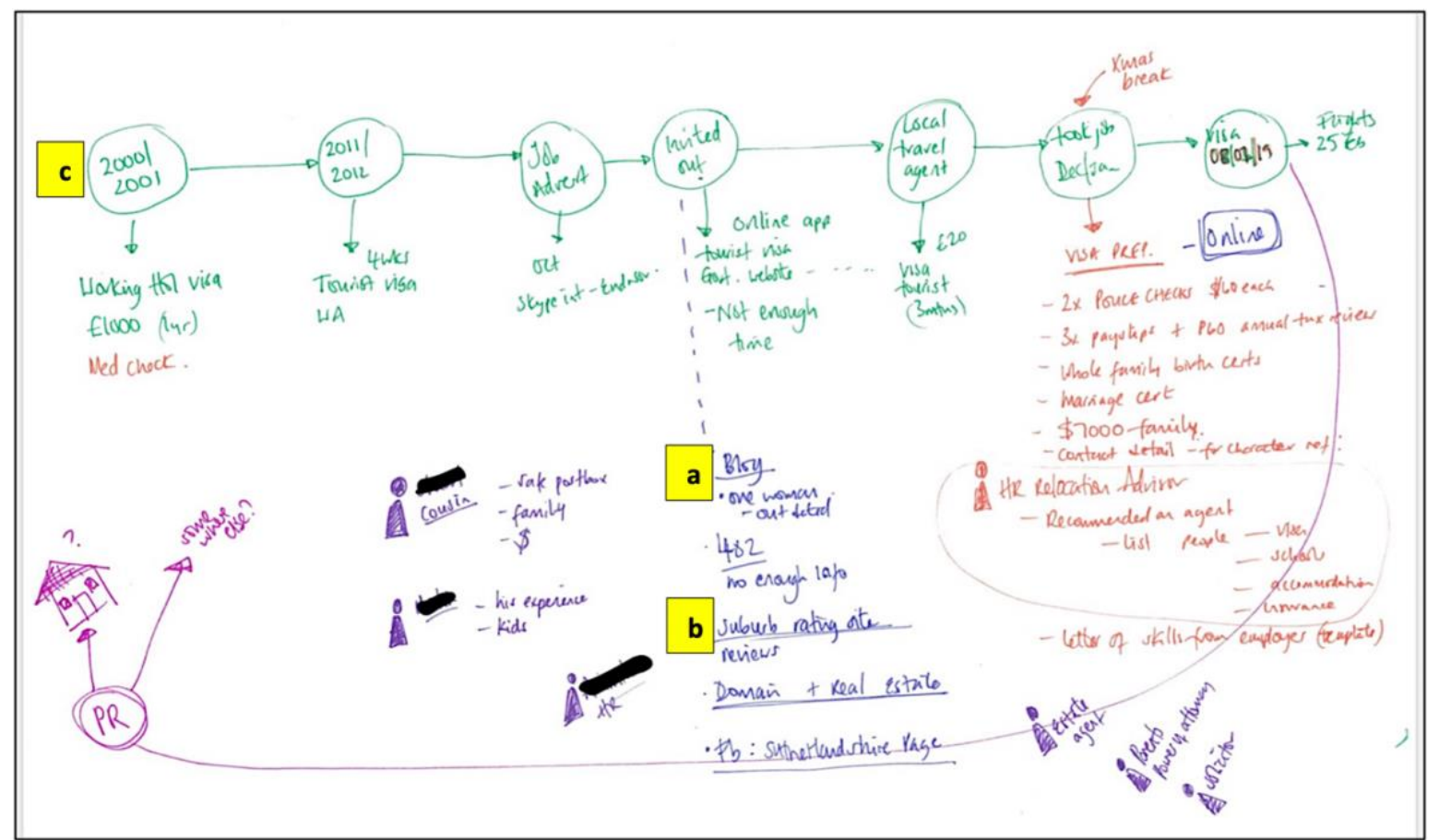

Figure 1. Lorraine's map: (a) Online blog for family migration, (b) Suburb rating site, (c) Migration timeline 


\section{Azwa}

Azwa arrived in Montreal on a visitor visa in 2018, after she got married to her partner who is a Canadian citizen. This was not the first time Azwa was moving. She describes that migration has always been a feature of her life. She spent her childhood in Botswana where her father worked on an expatriate visa. Through her work and education Azwa was constantly travelling and always aspired to a life somewhere else. In 2009, Azwa considered a move to Australia through its independent skilled migration program. At the same time, she also applied for a Fulbright scholarship for a master's degree in the US, which was successful. Upon returning back to Pakistan, Azwa started preparing documents for immigration to Canada through its express entry program. It is around this time that she was introduced to her husband by her family. After arriving and spending some time with her husband in Canada, she decided to switch her visa from 'visitor' to 'spouse.' Much of Azwa's map represents her transition across her changing marital and visa status.

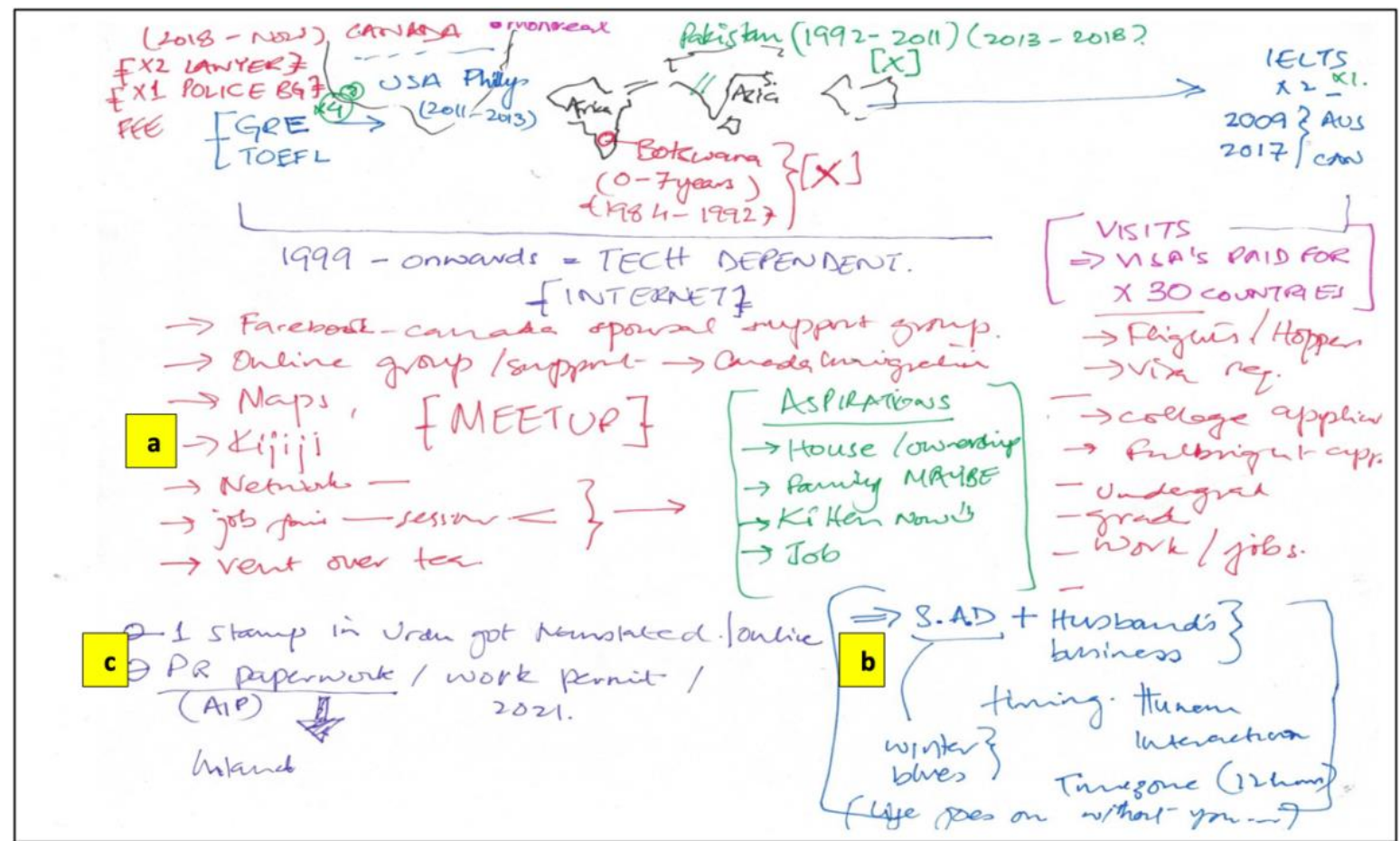

Figure 2. Azwa's map: (a) Online support - Facebook; vent over tea, (b) coping with SAD, (c) paperwork for PR

\section{Odin}

Odin moved to Melbourne as a permanent resident in April 2018 upon continued persuasion from his wife who completed her master's degree in Queensland but was not eligible for PR. Odin is a permanent resident of UK but met his wife, Naima in Nigeria while on a work project. He applied for his PR in 2013 and received it fairly quickly due to his occupation being in the priority demand list. Odin delayed his move to Australia due to his work commitments, and in 2018 just as his PR was about to expire, he moved to Melbourne. He continued working remotely with his UK employer while he lodged his wife and daughters visa application to join him in Australia. He planned to apply for local jobs and buy a house once his family arrives, as he wished to make those decisions together with them. When I 
interviewed him in July 2019, he was still waiting for their visas to be approved. Odin discussed how his life and plans were put on hold over this period of waiting, which he represents on his mind map.

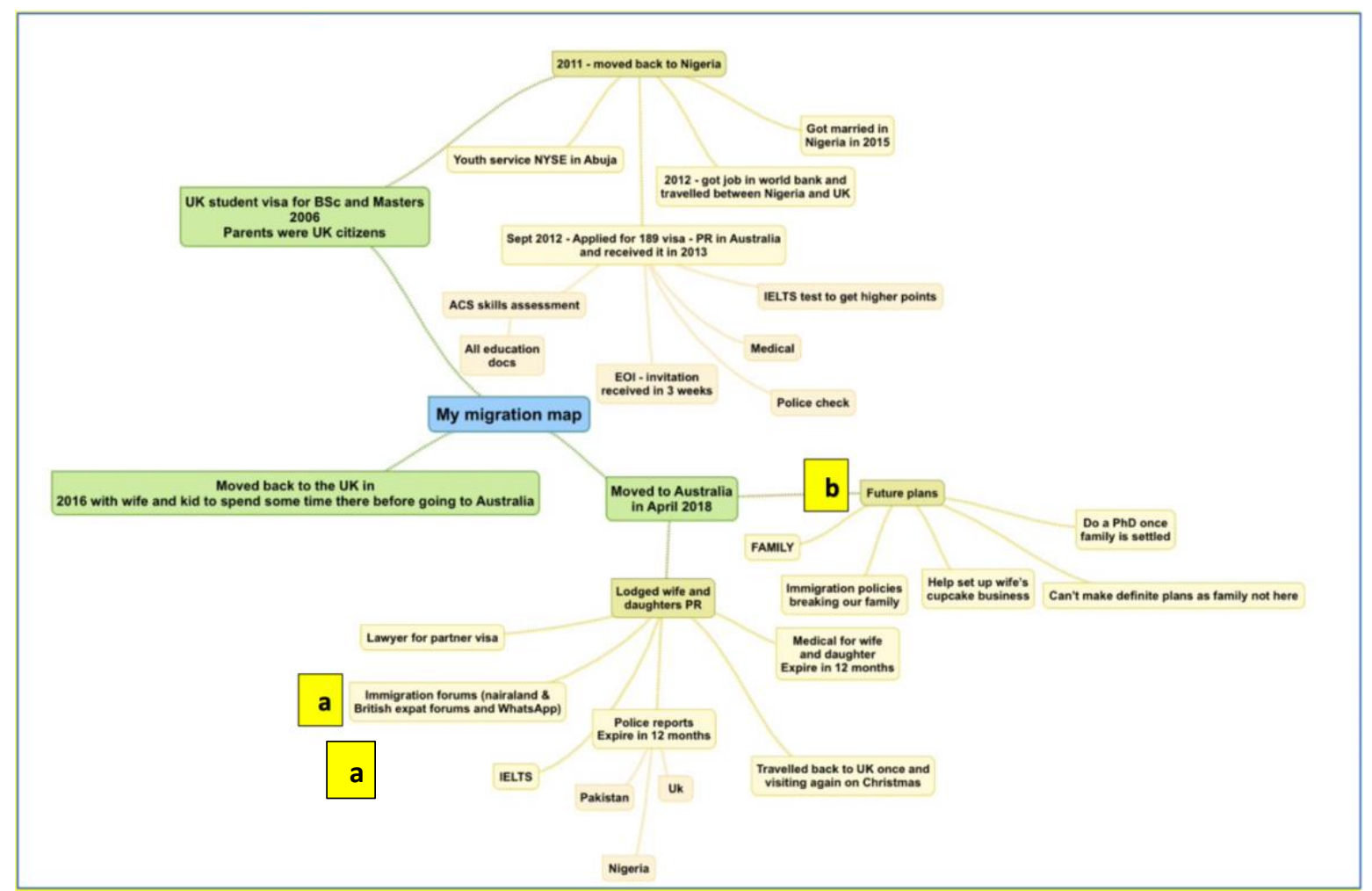

Figure 3. Odin's map: (a) Multiple online platforms, (b) future plans and aspirations

\section{Entwined online and offline social worlds}

A key feature in mind maps and participant narratives across this study is the use of digital media throughout different phases and circumstances of their migration journey. Migrants' use of social media and technology has received widespread scholarly attention that usually treats it as a single realm of inquiry, referred to by Pink et al. (2016), as "digitalmedia-centric-ness." Digital technology becomes a central focus in how it constraints or conditions migrant mobility through information, support, and connectivity (Oh, 2016; Marlowe et al., 2016). The maps presented in this study, however, suggest that technology infrastructures migrants use, are one component of a larger 'infrastructuring' process that consists of diverse practices, situations, and subjectivities (Lin et al., 2016). Participants' engagement with media is embedded in overlapping digital and offline social worlds, dispersed not only across different phases of departure, transit, arrival, and settlement, but also through individual lived realities.

Lorraine, for instance, highlights how social media played a specific role in providing her information about family migration in an academic mobility context that is largely focused on the single academic.

Things online, particularly for academic migration, were framed around the single academic (...) It was really difficult finding stories of family migration. I found one blog and I kept coming back to her (...) and it was things like thinking about 
schools, thinking about suburbs to live in (...) There's a site online where you can check the suburbs and they're given ratings for family friendly, or convenience, or distance from the city, and we ended up scouting that and finding out which suburbs might fit (...) that's the other thing - do move to a particular area to find a good school?

Lorraine's account demonstrates how digital and social infrastructures are intertwined through "everyday" aspects of "mediated migrants' lives" (Candidatu et al., 2019). Her use of online media enhances understandings of migration infrastructure, that is primarily concerned with mobility infrastructures that facilitate migration, but in fact, extend beyond the act of migration and become enmeshed within migrants' routine realities. Her digital practices revolve around ensuring that her family's relocation and transition is smooth. The media Lorraine used was narrowed down to an outdated online blog that concentrated on aspects of family migration such as housing, schooling, and neighbourhood research (figure $1(\mathrm{a})$ ). Her investigation on the suburb rating site and decision of where to live was also prioritised by the needs of her family (figure 1(b)). Similarly, Azwa's use of digital infrastructures is connected to multiple aspects of her 'new' life in Montreal.

It was not just a physical, geographical change, but it was also change in my marital status. So, I wanted to understand the dynamic of this relationship I was going to be in. Nobody hands you a JD for how to be a wife. What is it going to be like (...) plus SAD [seasonal affective disorder] so the timing was probably like the worst combination (...) We had so many fights and...when I went on the support group [Facebook], all couples have had fights doing this [spousal visa application] (...) I found Vent over tea (...) Basically, you go online, you book a venting session with somebody who's trained in active listening and you get an hour.

Azwa's account illustrates how different media platforms play a role in infrastructuring her socio-spatial experiences (Lin et al., 2017; Schapendonk et al., 2018). She uses google maps to navigate the geographical change of living in a new city; a Facebook spousal support group for information and advice on the spouse visa process and other marital issues; and 'vent over tea' for other aspects of her life in Montreal such as coping with SAD (figure 2(a)(b)). These narratives offer a critique on scholarly analyses of migration infrastructure that posits them as systems and technologies through which migrants are moved. Migrants are not simply passing through infrastructural domains but are actively seeking out, selecting, and engaging with them in diverse ways. Odin's use of digital media, for instance, shifts between receiving and providing advice.

So there's a WhatsApp group. We all chat about the experiences and all that. But, it's strictly for those who have been successful in their journey to discuss experiences of moving, finding work and so on. It was actually from there that I learnt that I should have actually applied for the partner [included partner in PR application] (...) Now, I'm actually active. I don't know much about other visas, but I do know about the 189 [Australian skilled independent] PR route (...) Now I tend to give advice to people... I tell people, 'hey if you're married, put your wife on your application.'

Advancing traditional understandings on migration infrastructure, Odin's account highlights how migrants themselves become an aspect of the infrastructure through information and advice they provide to others based on their own experiences. Moret (2018) 
identifies this as "mobility capital" that migrants accumulate and develop whilst "practicing mobility." At the time of his PR application, Odin did not know that he could add his partner in the same application. He only learnt this through his interactions with other migrants on a WhatsApp support group. He states how his own experiences urged him to become more active in providing migration advice to others on a similar pathway (figure 3(a)).

\section{Regulatory frameworks and migrant subjectivities}

Scholarly inquiry on regulatory infrastructures in migration have predominantly considered them as an aspect of departure arrangements, or procedures that are performed at the border including vetting, medical examinations, character assessments and so on (Bloom, 2015). There is a dearth of literature on regulatory processes that migrants go through post arrival. Exceptions include works from Meeus et al. (2018) on "arrival infrastructures" as systems that newcomers engage with upon arrival, and through which their future social mobilities are produced and negotiated. Drawing from this body of work, narratives in this section demonstrate how skilled migrants, who arrive with different legal and social statuses are subjected to diverse regulatory requirements, and how their actions and negotiations with these infrastructures shape their mobilities further. Azwa, for instance, narrates her experiences of the paperwork involved in switching her visa:

The paperwork itself is this one is the worst paperwork I've done in my life. I could have applied to five universities in that one paperwork (...) We've been married for less than a year when we applied so we had to actually prove that this was a legitimate real marriage. (...) We had to think really out of the box in terms of what we give them... so, like, we give them photographers contract for the wedding, permission slips for wedding shoots, receipts of the cake, the wedding catering (...) and everything needs to be translated in English.

Azwa's change of visa status is mobilised by the mundane artefacts and objects that she uses translation services for (figure 2(c)), pointing to the hidden or taken for granted nature of processes involved in shaping migrant mobilities (Bork-Hüffer \& Yeoh, 2017). Her account further demonstrates key human interventions of planning, strategy, and thinking 'outside the box' in making decisions around regulatory requirements. Her evidence for the visa application included articles from her wedding such as catering and photography receipts, but it is the process of collecting, translating, collating, and deciding upon what to include or omit is what Azwa stresses upon in her narrative.

For Lorraine, however, regulatory requirements extend beyond her own visa status. Being on a temporary visa, she does not qualify for subsidised schooling for her children and is required to pay an education fee to the government. Considering the costs involved, she contemplates if her move to Australia is worth it.

I guess in this whole process, we were realising how much money it was gonna cost and thinking 'is it worth it?' (...) We have to pay education fees here. We have to pay the government fee of $\$ 5200$ per child per year to go to school (...) I can't afford that (...) We're on one wage. $70 \%$ of my wages is going on accommodation which is crazy (...) I don't want to start chipping away our house money coz once we start, it's gonna be gone (...) So, we're paying in 2 blocks. It is still a lot of money. 
Although Lorraine's mobility is considerably privileged, in that, she has arrived on a highly skilled visa and has a preferential pathway to PR and citizenship, she reflects upon it being "worth it" for her family financially. Her decision of moving with her family exposes her to power asymmetries of supportive and exclusionary governmental infrastructures (Meeus et al., 2018). For Lorraine, her mobility was smooth, even as she depicts it on her map as a linear timeline (figure 1(c)), but it is the transition that she finds challenging. This narrative further exemplifies the problematic nature of using policy categories for research which eradicates the multiplicity of migrant's struggles and negotiations. Lorraine tells me how she negotiated to pay the fees in two blocks highlighting several financial and social aspects of her everyday family life in a new place.

Migrant negotiations with the regulatory apparatus of the state are also shaped by aspirations, and desires of the future. "People do not aspire to migrate; they aspire to something which migration might help them achieve" (Carling \& Collins, 2018, p. 917). Odin's struggles with regulatory mechanisms in bringing his family over, for example are connected to his future aspirations of a global career, buying a house and starting a business:

The good thing about my work is that you can move around. But that would happen when my family is here and fully stabilised. I can't do that now. Again, that's one of the pain I am feeling with this kind of migration - it makes things difficult for me for planning (...) Because my wife if not here, it's a bit difficult to make a definite plan. For example, I would have gotten a mortgage by now. My bank already offered me a loan to buy a house, but I don't wanna do anything until my wife comes. I'm also thinking of starting a business in Australia with my wife - we can partner together.

In talking about the 'pain he feels' from his encounters with regulatory mechanisms of family migration, Odin's story draws attention to emotions and 'states of feeling' involved the process of migration and aspired futures enabled by migration (Carling \& Collins, 2018). In Odin's case, these subjectivities are embedded in imagined geographies of a global career, emotional depositions of being unable to plan, social relations and obligations towards his wife and family in making decisions of buying a house, and the politics and power relations of going through immigration processing (figure 3(b)).

\section{Conclusion}

Studies on "migration infrastructure calls for research that is less fixated on migration as behaviour or migrants as the primary subject" (Xiang \& Lindquist, 2014, p. 122). Migrants themselves take a back seat as the focus is not on how migrants move but how they are moved. Through an analysis of migrants' interactions with technology and regulatory infrastructures in this study, this paper demonstrates that such a framing discounts the role of migrants as active agents with social and material resources that they use to negotiate and navigate diverse aspects of their lives.

By zooming into migrants' interactions with technological and regulatory infrastructures, this paper argues for a more holistic understanding of skilled migration processes that are entwined with participants' social and individual subjectivities. Much of the work on infrastructural mechanisms in migration studies tends to focus on singular aspects of these assemblages. We have seen for example, a vast array of scholarship focused on migrants use of digital technologies (Leurs \& Ponzanesi, 2018; Pink et al., 2016; 
Oh, 2016). While these studies have uncovered important ways in which migrants interact with digital and media infrastructures, the narratives in this paper demonstrate that these infrastructures are one aspect of the migration process, and their use depends upon migrants' personal circumstances and needs. Migrants play an active role in choosing and switching between media platforms; and between receiving and providing advice.

Furthermore, a majority of scholarship conducted on migration infrastructures are based within sending contexts focusing on aspects of departure. As this paper shows, migrants encounter new and diverse types of regulatory infrastructures upon their arrival based on their legal and social status. The narratives demonstrate how participants' plans, negotiations, and aspirations are enmeshed with regulatory infrastructures and migrants are involved in constant negotiations with these systems as they move across different stages in their journeys.

This paper attempts to redirect thinking on migration infrastructures by focusing on the lived experiences of infrastructures as the entry point in analysing migrant mobility. Mapping experiences of onshore migrants provides a methodological basis for following migrants lifecourses rather than the dominant focus on departure, transit, and arrival or on analyses of policy categories. I draw attention, instead, to the lived experiences of 'migration as a process' which is dynamic, multifarious, and ongoing. 


\section{References}

Alpes, M. J. (2017). Why aspiring migrants trust migration brokers: the moral economy of departure in Anglophone Cameroon. Cambridge University Press, 87(2), 304-321.

Aparna, K., \& Schapendonk, J. (2018). Shifting itineraries of asylum hospitality: Towards a process geographical approach of guest-host relations. Geoforum - Special Issue: Re-routing migration geographies: migrants, trajectories and mobility regimes.

ABS. (2018). Net overseas migration, arrivals and departures, state/territory, major groupings and visa - calendar years 2004 to 2017. Migration Australia, 2016-17. Retrieved http://www.abs.gov.au/AUSSTATS/abs@.nsf/DetailsPage/3412.0201617? OpenDocument

Baas, M. (2017). The mobile middle: Indian skilled migrants in Singapore and the 'middling' space between migration categories. Transitions: Journal of Transient Migration, 1(1), 47-63.

Beech, S. E. (2018). Adapting to change in the higher education system: International student mobility as a migration industry. Journal of Ethnic and Migration Studies, 44(4), 610-625.

Bloom, T. (2015). The business of migration control: Delegating migration control functions to private actors. Global Policy, 6(2), 151-157.

Boccagni, P. (2017). Migration and the search for home: Mapping domestic space in migrants' everyday life. New York: Palgrave Macmillan.

Bork-Hüffer, T., \& Yeoh, B. S. A. (2017). The geographies of difference in conflating digital and offline spaces of encounter: Migrant professionals' throwntogetherness in Singapore. Geoforum, 86, 93-102.

Campos-Delgado, A. (2018). Counter-mapping migration: Irregular migrants' stories through cognitive mapping. Mobilities, 13(4), 488-504.

Carling, J., \& Collins, F. (2018). Aspiration, desire and drivers of migration. Journal of Ethnic and Migration Studies, 44(6), 909-926.

Chan, C. (2017). In between leaving and being left behind: Mediating the mobilities and immobilities of Indonesian non-migrants. Global Networks, 17(4), 554-573.

Cho, L. (2017). Mass capture: The making of non-citizens and the Mainland Travel Permit for Hong Kong and Macau Residents. Mobilities, 12(2), 188-198.

Collins, F. (2018). Desire as a theory for migration studies: Temporality, assemblage and becoming in the narratives of migrants. Journal of Ethnic and Migration Studies, 44(6), 964-980.

Cranston, S. (2016). Producing migrant encounter: Learning to be a British expatriate in Singapore through the Global Mobility Industry. Society and Space, 34(4), 655-671.

Cranston, S. (2018). Calculating the migration industries: Knowing the successful expatriate in the Global Mobility Industry. Journal of Ethnic and Migration Studies, 44(4), 626643.

Cranston, S., Schapendonk, J., \& Ernst, S. (2018). New directions in exploring the migration industries: Introduction to special issue. Journal of Ethnic and Migration Studies, 44(4), 543-557.

Czaika, M., \& Parsons, C. R. (2017). The gravity of high-skilled migration policies. Demography, 54(2), 603-630.

DHA. (2019). Australia's skilled visas. Department of Home Affairs. Retrieved from: https://www.homeaffairs.gov.au/trav/work/skilledvisas.

Dijstelbloem, H. (2017). Migration tracking is a mess. Nature, 543(7643), 32-34.

Faist, T. (2014). Brokerage in cross border mobility: Social mechanisms and the (re)production of social inequalities. Social Inclusion, 2(4), 38-52. 
Fernandez, B. (2013). Traffickers, brokers, employment agents and social networks: The regulation of intermediaries in the migration of Ethiopian domestic workers in the middle east. International Migration Review, 47(4), 814-843.

Folse, B. J. (2017). Aspirational Migration: The Case of Chinese Birth Tourism in the U.S. University of Oregon.

Franck, A. K., Arellano, E. B., \& Anderson, J. T. (2018). Navigating Migrant Trajectories through Private Actors: Burmese Labour Migration to Malaysia. European Journal of East Asian Studies, 17, 55-82.

Friberg, J. H. (2016). The Rise and Implications of Temporary Staffing as a Migration Industry in Norway. Nordic Journal of Migration Research, 6(2), 81-91.

Gammeltoft-Hansen, T., \& Sorensen, N. (Eds.). (2013). The migration industry and the commercialization of international migration. London: Routledge.

Ghosh, S. (2014). A Passage to Canada: The Differential Migrations of South Asian Skilled Workers to Toronto. Journal of International Migration and Integration, 15(4), 715-735.

Goh, C., Wee, K., \& Yeoh, B. S. A. (2017). Migration governance and the migration industry in Asia: moving domestic workers from Indonesia to Singapore. International relations of the Asia-Pacific, 17(3), 401-433.

Harvey, W. S., Groutsis, D., \& van den Broek, D. (2018). Intermediaries and destination reputations: explaining flows of skilled migration. Journal of Ethnic and Migration Studies, 44(4), 644-622.

Hawthorne, L. (2015). The Impact of Skilled Migration on Foreign Qualification Recognition Reform in Australia. Canadian Public Policy, Project MUSE, University of Toronto Press, 41(1), 173-187.

Hirish, M. (2017). Emerging infrastructures of low-cost aviation in Southeast Asia. Mobilities, 12(2), 250-276.

Hopkins, J. (2016). A Comparative Study Examining Academic Cohorts with Transnational Migratory Intentions Towards Canada and Australia. Higher Education Quarterly, 70(3), 246-263.

Jung, H. (2014). Let Their Voices Be Seen: Exploring Mental Mapping as a Feminist Visual Methodology for the Study of Migrant Women. International Journal of Urban and Regional Research, 38(3), 985-1002.

Koh, S. Y., \& Wissink, B. (2018). Enabling, structuring and creating elite transnational lifestyles: Intermediaries of the super-rich and the elite mobilities industry. Journal of Ethnic and Migration Studies, 44(4), 592-609.

Koslowski, R. (2013). Selective migration policy models and changing realities of implementation. International Migration, 52(3), 26-39.

Larkin, B. (2013). The Politics and Poetics of Infrastructure', Annual Review of Anthropology, 42(1), 327-343.

Leurs, K., \& Ponzanesi, S. (2018). Connected migrants: Encapsulation and cosmopolitization. Popular Communication, 16(1), 4-20.

Lindquist, J. (2017). Brokers, channels, infrastructure: Moving migrant labour in the Indonesian-Malaysian oil palm complex. Mobilities, 12(2), 213-226.

Lim, S. S., \& Pham, B. (2016). 'If you are a foreigner in a foreign country, you stick together': Technologically mediated communication and acculturation of migrant students. New Media and Society, 18(10), 2171-2188.

Lin, W., Lindquist, J., Xiang, B., \& Yeoh, B. S. A. (2016). Migration infrastructures and the production of migrant mobilities. Mobilities, 12(2), 167-174.

Liu, T. \& Lin, W. (2017). Transnational work and workplace as infrastructure: Sino-British international branch campuses and academic mobilities. Mobilities, 12(2), 277-293.

Lynch, K. (1960). The image of the City. Cambridge: MIT Press. 
Mares, P. (2016). Not quite Australian: How temporary migration is changing the nation. Melbourne: The Text Publishing Company.

Marlowe, J. M., Bartley, A., \& Collins, F. (2016). Digital belongings: The intersections of social cohesion, connectivity and digital media. Ethnicities, 17(1), 85-102.

Massa, A. (2018). Borders and boundaries as resources for mobility. Multiple regimes of mobility and incoherent trajectories on the Ethiopian-Eritrean border. Geoforum.

Mcauliffe, M., \& Ruhs, M. (2017). World Migration Report 2018. International Organisation for Migration. Retrieved from: https://publications.iom.int/system/files/pdf/wmr_2018_en_chapter1.pdf.

McCollum, D., \& Findlay, A. (2018). Oiling the wheels? Flexible labour markets and the migration industry. Journal of Ethnic and Migration Studies, 44(4), 558-574.

Meeus, B., van Heur, B., \& Arnaut, K. (2018). Migration and the Infrastructural Politics of Urban Arrival. In B. Meeus, B. van Heur, \& K. Arnaut (Eds.), Arrival Infrastructures: Migration and Urban Social Mobilities (pp. 1-32). New York: Palgrave Macmillan.

Moret, J. (2018). Mobility capital: Somali migrants' trajectories of (im)mobilities and the negotiation of social inequalities across borders. Geoforum.

Oh, J. (2016). Immigration and social capital in a Korean-American women's online community: Supporting acculturation, cultural pluralism, and transnationalism. New Media and Society, 18(10), 2224-2241.

Papadopoulos, D., \& Tsianos, V. (2008). The autonomy of migration: The animals of undocumented mobility. University of Leicester. Retrieved from: https://www2.le.ac.uk/departments/business/research/units/cppe/archiveactivities/tex ts/2007-Migration-DeleuzianEncounters-Papadopoulos-Tsianos.PDF

Pink, S., Horst, H., Postill, J., Hjorth, L., Lewis, T., \& Tacchi, J. (2016). Digital ethnography. Principles and practice. London, UK: Sage.

Ramos, C. (2018). Onward migration from Spain to London in times of crisis: The importance of life-course junctures in secondary migrations. Journal of Ethnic and Migration Studies, 44(11), 1841-1857.

Rechniewski, E., \& Graves, M. (2015). Imagining geographies, mapping identities. Journal of Multidisciplinary International Studies, 12.

Robertson, S. (2014). The temporalities of international migration: Implications for ethnographic research. Institute for Culture and Society Occasional Paper Series, 5, $1-16$.

Robertson, S. (2017). Infrastructures of insecurity: Housing and language testing in AsiaAustralia migration. Geoforum, 82, 13-20.

Robertson, S. (2018). Migrant, interrupted: The temporalities of 'staggered' migration from Asia to Australia. Current Sociology, 67(2), 169-185.

Salt, J. \& Stein, J. (1997). Migration as a business: The case of trafficking. International Migration, 35(4), 467-494.

Schapendonk, J. (2018). Navigating the migration industry: Migrants moving through an African-European web of facilitation/control. Journal of Ethnic and Migration Studies, 44(4), 663-679.

Schapendonk, J., van Liempt, I., Schwarz, I., \& Steet, G. (2018). Re-routing migration geographies: Migrants, trajectories and mobility regimes. Geoforum.

Schwarz, I. (2018). Migrants moving through mobility regimes: The trajectory approach as a tool to reveal migratory processes. Geoforum.

Spaan, E., \& van Naerssen, T. (2018). Migration decision-making and migration industry in the Indonesia-Malaysia corridor. Journal of Ethnic and Migration Studies, 44(4), 680695.

Spener, D. (2009). Some critical reflections on the migration industry concept. Department of Sociology and Anthropology, Trinity University, 1-41. 
Statista. (2019). Number of immigrants in Canada, by province and territory of residence. Demographics. Retrieved from: https://www.statista.com/statistics/444906/number-ofimmigrants-in-canada/.

Thieme, S. (2017). Educational consultants in Nepal: Professionalization of services for students who want to study abroad. Mobilities, 12(2), 243-258.

Triandafyllidou, A. (2017). Beyond irregular migration governance: Zooming in on migrants' agency. European Journal of Migration and Law, 19(1), 1-11.

Tuckett, A. (2018). Ethical brokerage and self-fashioning in Italian immigration bureaucracy. Critique of Anthropology, 38(4), 1-20.

Underhill, E., Groutsis, D., van den Broek, D., \& Rimmer, M. (2016). Migration intermediaries and codes on conduct: Temporary migrant workers in Australian horticulture. Journal of Business Ethics, 153(3), 1-15.

Walsh, J. (2014). From nations of immigrants to states of transience: Temporary migration in Canada and Australia. International Sociology, 26(6), 584-606.

Xiang, B. (2017). The base: A case of infrastructural governance of labor outmigration in China. Mobilities, 12(2), 175-187.

Xiang, B., \& Lindquist, J. (2014). Migration Infrastructure. International Migration Review, 8(1), 122-148.

Yeoh, B. S. A., Chee, H. L., \& Baey, G. (2017). Managing risk, making a match: brokers and the management of mobility in international marriage. Mobilities, 12(2), 227-242. 